\title{
A Survey of Simulation Tools for Waterway Designing Assessment
}

\author{
Wei $\mathrm{He}^{1, *}$, Enjun Wang ${ }^{2}$, Xinglong $\mathrm{Liu}^{3}$ and Chenguang $\mathrm{Liu}^{3}$
}

\author{
${ }^{I}$ Transportation Engineering Institute, Minjiang University, Fuzhou, P. R. China; Intelligent Transportation System Re- \\ search Center, Wuhan University of Technology, Wuhan, P. R. China; Engineering Research Center for Transportation \\ Safety (Ministry of Education), Wuhan, P.R. China; Research and Development Base on Waterway Transportation Safe- \\ ty and Anti-pollution of CJRDC (Ministry of Transport) Wuhan \\ ${ }^{2}$ Research Center, Wuhan Institute of Technology, Wuhan, P. R. China \\ ${ }^{3}$ Intelligent Transportation System Research Center, Wuhan University of Technology, Wuhan, P. R. China; Engineering \\ Research Center for Transportation Safety (Ministry of Education), Wuhan, P. R. China; Research and Development \\ Base on Waterway Transportation Safety and Anti-pollution of CJRDC (Ministry of Transport) Wuhan
}

\begin{abstract}
Simulation is one of the effective tools for the assessment of waterway designing. The system constitution and procedure of waterway simulation are introduced, and key technologies of waterway simulation system are analyzed, including vessel dynamics modeling, vessel traffic flow modeling, waterway scenery modeling and assessment methods. Moreover, the design the simulation system of inland waterway is prospected.
\end{abstract}

Keywords: Aid-to-navigation, geographic information systems, virtual Reality, Waterway.

\section{INTRODUCTION}

Simulation is performed through the use of a model to reproduce and imitate the real process occurring in the system. It can evaluate the system performance and operational risks of the real or designed system through experimentation of the system model. When the designed system is supposed to have high cost, or it is dangerous or takes a long time to understand the outcomes caused by changes of system parameters, simulation is a very effective alternative for research. Simulation process includes two main steps: the establishment of simulation models and simulation experiments. Waterways and navigation aids are important transportation facilities. The amount of investment in waterways is huge and operational uncertainties in the process are also increasing. Recently, simulation technology has found a wide range of applications in the field of waterway engineering design and planning. Through accurate model and high fidelity waterway traffic scene, simulation can effectively assess waterways and operating performance and identify potential risks before the navigation aids is put into use. Therefore, it can improve waterway traffic safety, and increase the carrying capacity.

In Europe, the Netherlands Institute developed real-time simulation models and software for handling sailing ships in port, which was successfully applied to the design of the Port of Rotterdam Waterway [1, 2]. German Research Center of the University of Duisburg on shipping developed a simulator system for the ship in shallow inland waterway which is used to evaluate the designs and train the inland vessel driver [3]. University of Liège, Belgium, developed an inland navigation simulation system which is used for evaluating Locks and the designing of the restricted waters navigation aids [4]. In China, Chen Shenyang carried out research on vessel traffic flow simulation of port and channel. Through the port vessel traffic flow modeling and real-time simulation, the ship route in port was planned [5]. Qian Zhonghua explored the method of using ship handling simulator to the design and argument of ports and waterways [6]. Kong Xianwei and others studied how the marine navigation simulator worked in the Layout of the crossing of Ji Han River and Yangtze River [7]. With national attention on inland waterways, inland waterway construction will be of great development. Because of the special environment, simulation technology applied to the inland waterways and facilities aiding navigation still needs to resolve many of the key design techniques and methods [8]. This article will summarize the current channel simulation technology and system structure characteristics, development status, and analyze the key technology and prospective application developments in the inland waterway system.

\section{ONOVERVIEW OF SIMULATION OF WA- TERWAY ENGINEERING DESIGN EVALUATIN}

Waterway engineering design simulation process includes the establishment of the simulation planning and the conduct of simulation experiment. The simulation planning process includes determining objectives, defining the various input parameters, planning specific simulation implementation ways, putting forward system functional requirements of 
simulation software. Simulation experiment is the implementation of simulation and the analysis of experimental results.

\section{A. Objectives and Conditions of Waterway Engineering Design Evaluation Simulation}

Before conducting the simulation of waterway engineering design evaluation, a preliminary analysis based on risk assessment should be carried out and some basic input parameters for the simulation analysis should be provided, thus ensuring the accuracy of the simulation results. Usually in the analysis phase, it should at least include the following aspects: (1) the aims of the designed aid navigation systems; (2) clear the designed geographic extent and navigation aids locations, observation time, investment and other constraints expressly; (3) clear the basic elements of the navigable waterway which includes: the type of ship, route, ship density, hydrological and meteorological conditions, boats interaction and minimal visibility; (4) clear some flags such as: landmark, danger signs, guide signs, navigational aids and the type during the waterway design.

\section{B. Implementation Planning of Waterway Engineering Design Evaluating Simulation Program}

Implementation planning of waterway engineering design evaluating simulation program is to determine the main simulation research, personnel participating in the experiment, simulation software and equipment. The implementations of design evaluation simulation on waterways and navigation aids include (1) assessment of the design parameters of the navigation aids such as the form of placing, location, type, characteristics, and quantity; (2) evaluation of the effects of the layout of fairway and port on ship safety and efficiency; (3) assessment of the navigation environment like wind, wave, current, quay effects, and visibility, and the role of background light played in ship safety, etc. Driving "Human-in-the-loop" waterway design simulation through a full mission ship simulator is the most ideal model. Simulation laboratory personnel involved should include waterway designers, ship pilots, marine management, and the designers of simulation system. Therefore, simulation process can be made close to reality and fair and objective. Simulation software is the core support of the system simulation experiment. To implement the waterway and navigation aids, designed to evaluate simulation experiments, the software should have the following features: (1) before the design of waterways and aids, the user can browse the spatial position of the relevant waterway; (2) the navigation system performance analysis of different design solutions of navigation aids can be done; (3) provide high-quality waterway terrain and port information data source; (4) the visual effects and light pollution of navigation aids can be evaluated; (5) the radar images can be evaluated; (6) the efficacy of various aids, such as lights, beacons, AIS (ship identification system), and the VTMS (Vessel Traffic Management System) can be effectively assessed; (7) The ship maneuvering characteristics for various types can be evaluated; (8) The ship speed especially the requirements of high-speed vessels on navigation aids can be assessed; (9) The various visibility effects in the daytime or at night can be estimated; (10) The various hydrological conditions can be simulated; (11) Ships and navigation aids facilities can be observed from different perspectives ; (12) A variety of traffic information data such as radar and AIS can be superimposed; (13) The marine electronics navigation system; (14)The simulation of several vessels can be allowed and their interactions can be displayed and observed; (15) The manipulation of various tugs can be simulated; (16) The accuracy and performance of various ship positioning system can be evaluated.

\section{Requirments of Waterway Engineering Design Eval- uating Simulation Analysis}

After simulation, there is the need for in-depth analysis of the evaluation results, and thus forming assessment documents. Assessment documentation should include the following: (1) simulation evaluation objectives; (2) simulation evaluation methods; (3) a description and modeling of the simulation system ship; (4) the description of waterways, navigation aids and navigable conditions in simulation system; (5) the navigation environment dynamics and depth information modeling; (6) emulation system components; (7) records of the experiment; (8) experimental data analysis; (9) experimental conclusions and recommendations, such as the size of the ship, the impact ship motion has on the navigation aids, environmental constraints of navigation, visibility conditions, ship sailing conditions in restricted waters, the layout of navigation aids, waterway scale and so on. In addition, the recommendations of the conditions of tugs in use, technical requirements of pilot and training shall be entailed.

In building a simulation system, it is necessary to do some prior processing of the basic input data in order to meet the demand of the data format and data traffic of the simulation system. To make the simulation system with high accuracy and fidelity, the parameters of hydrology, graphics, ship, positioning and navigation, weather conditions and other input data in particular should match the simulation environment [9].

\section{CHANNEL SIMULATION SYSTEM AND FEA- TURES}

\section{A. Waterway Simulation System Based on the Ship Driv- ing Simulator}

Based on the ship simulation technology, the establishment of simulation system is currently the major technique of design evaluation simulation related to islands navigation aids. The typical channel simulation systems are realtime simulation systems, desktop simulation system, partmission task simulators and full mission simulator are shown in Fig. (1). The features and the scope of application are shown in Table 1. Fast real-time simulation system is a twodimensional simulation which does not allow for the human in the loop, using the autopilot to replace helmsman, the model structure of it is shown in Fig. (2). The input data includes ship parameters, channel information, and hydrological and 


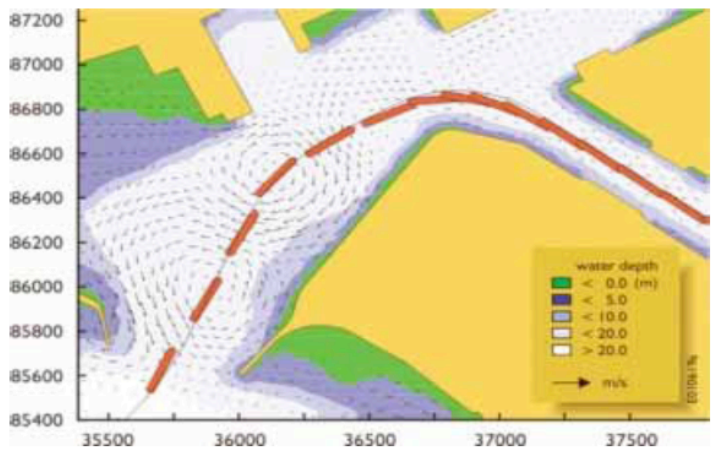

A. Fairway fast simulation system interface (SHIPMA)

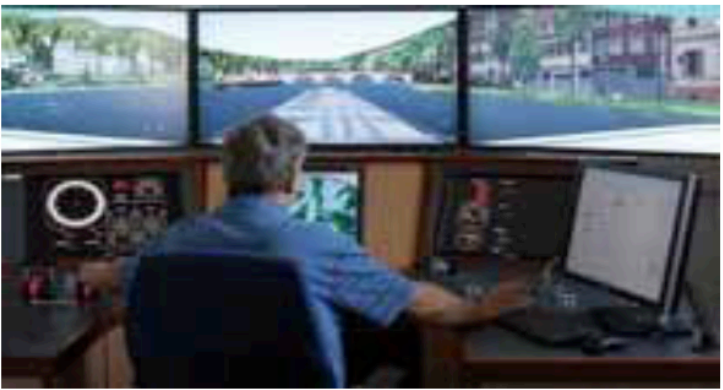

C. Part-mission simulation system (BAW)

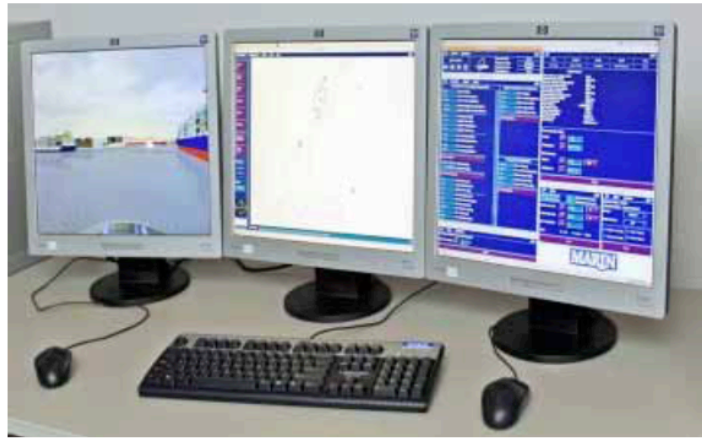

B. Channel Desktop Simulation System (MARIN)

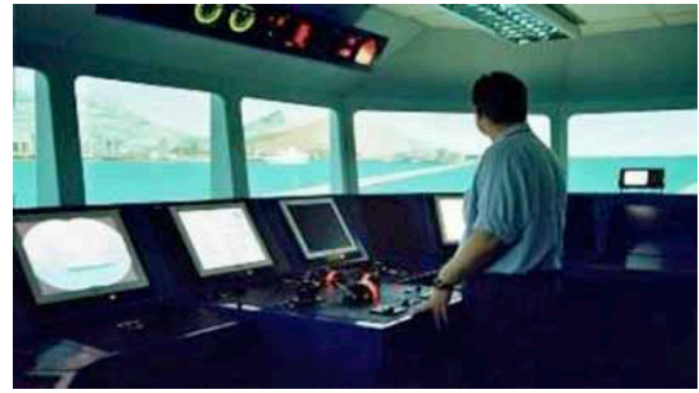

D. Full-mission Driving Simulator(MARIN)

Fig. (1). Typical channel simulation system.

Table 1. Channel simulation system characteristics and applicability.

\begin{tabular}{|c|c|c|c|}
\hline$\underset{\text { Type }}{\text { Feature }}$ & Advantages & Disadvantages & Scope of Application \\
\hline $\begin{array}{l}\text { Fast real-time simula- } \\
\text { tion system }\end{array}$ & $\begin{array}{l}\text { - can quickly provide quantitative analysis re- } \\
\text { sults by analyzing the design feasibility of wa- } \\
\text { terways and navigation aids; } \\
\text { - } \quad \text { can quickly evaluate multiple waterway scene, } \\
\text { and can easily change the scene; } \\
\text { - conducive to use for individual and consulting } \\
\text { units; } \\
\text { - allows for offline simulation, and can quickly } \\
\text { get simulation results; } \\
\text { can quickly provide the ship track distribution } \\
\text { in the channel; } \\
\text { - Can provide a cost-benefit analysis. }\end{array}$ & $\begin{array}{l}\text { - } \text { simulation system speed depends on } \\
\text { hardware capabilities; } \\
\text { - simulation process does not allow dy- } \\
\text { namic changes; } \\
\text { - cannot evaluate manmade factors; } \\
\text { - In simulation process, nobody in the } \\
\text { loop; } \\
\text { - Cannot consider waterway traffic man- } \\
\text { agement in the simulation process. }\end{array}$ & $\begin{array}{l}\text { - } \quad \text { waterway scale design and } \\
\text { evaluation; } \\
\text { - Test of full-mission simu- } \\
\text { lator waterway scene; } \\
\text { - } \quad \text { the estimation of lay-out } \\
\text { parameter in navigation } \\
\text { aids system; } \\
\text { - Assessment of vessel us- } \\
\text { ing the automatic rudder } \\
\text { ship track distribution. }\end{array}$ \\
\hline
\end{tabular}


Table 1. contd...

\begin{tabular}{|c|c|c|c|}
\hline$\underset{\text { Type }}{\text { Feature }}$ & Advantages & Disadvantages & Scope of Application \\
\hline $\begin{array}{l}\text { Part-mission simula- } \\
\text { tion system }\end{array}$ & $\begin{array}{l}\text { - the simulator can be used to conduct interac- } \\
\text { tive experiment when connecting with other } \\
\text { types; } \\
\text { - has a good sense of on-site immersion; } \\
\text { - mariners can join the simulation; } \\
\text { - Relatively easy to install. }\end{array}$ & $\begin{array}{l}\text { - a higher cost for building and maintain- } \\
\text { ing; } \\
\text { - In the simulation experiment, capabilities } \\
\text { of HCI is weaker than full-mission simu- } \\
\text { lator; } \\
\text { - Operating handle sand instruments in the } \\
\text { simulator lack a sense of reality. }\end{array}$ & $\begin{array}{l}\text { - Assessment of the effect } \\
\text { of navigation aids; } \\
\text { - waterway design evalua- } \\
\text { tion }\end{array}$ \\
\hline $\begin{array}{c}\text { Full mission simulation } \\
\text { system }\end{array}$ & $\begin{array}{l}\text { - } \quad \text { very real } \mathrm{HCI} \text {; } \\
\text { - can accurately evaluate various scenarios; } \\
\text { - high immersion in experimental systems loop; } \\
\text { - dynamic parameters can be modified in real } \\
\text { time; }\end{array}$ & $\begin{array}{l}\text { - equipment is too expensive; } \\
\text { - Not suitable for preliminary cost analy- } \\
\text { sis; } \\
\text { - Inconvenient to use, not suitable for all } \\
\text { users. }\end{array}$ & $\begin{array}{l}\text { - assessment of effect of } \\
\text { navigation aids; } \\
\text { - Final waterway design } \\
\text { evaluation. }\end{array}$ \\
\hline
\end{tabular}

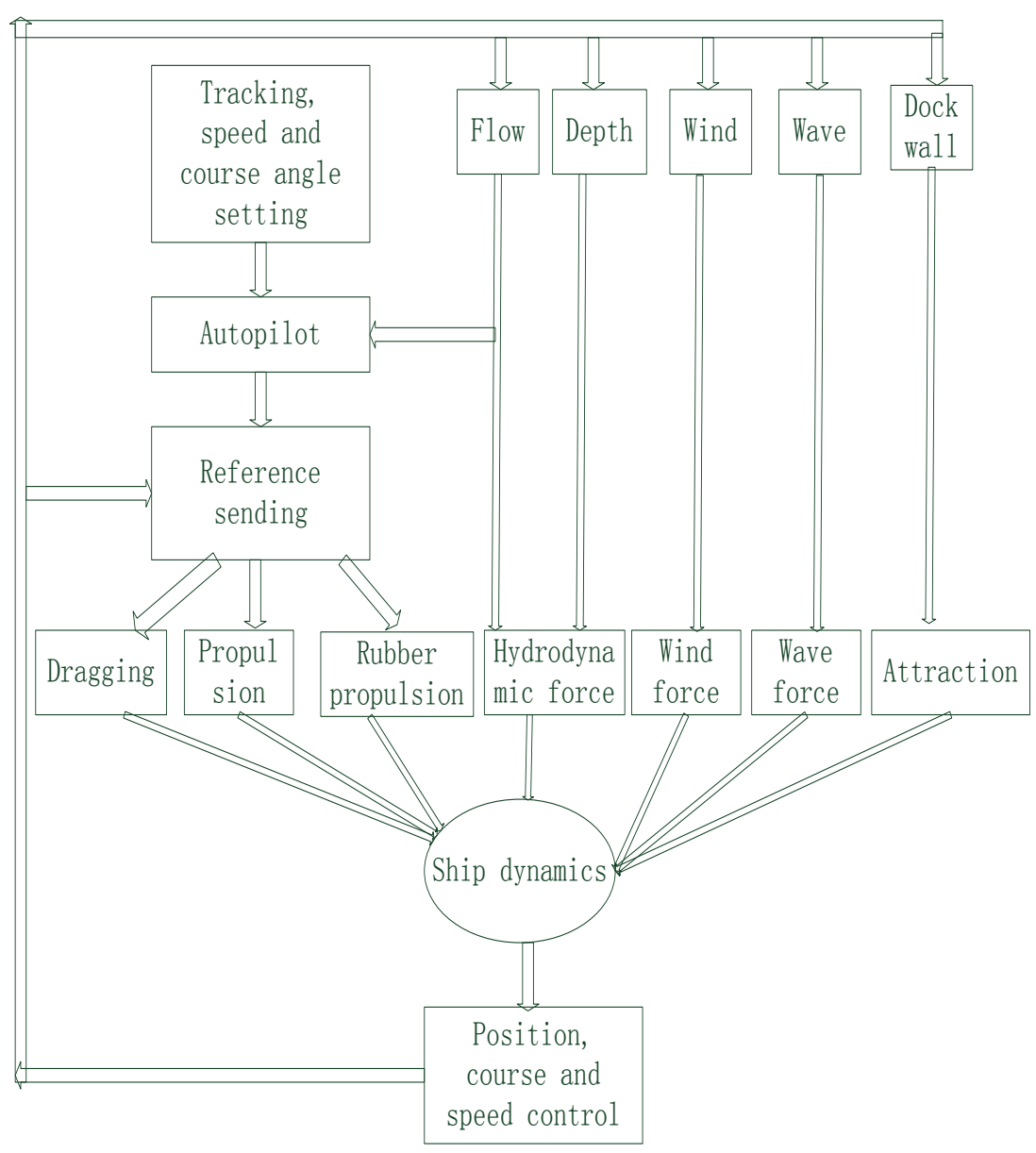

Fig. (2). Waterway fast real-time simulation model structure.

meteorological information. The ship's motion model adopts 6 degree of freedom model to obtain accurate vessels simulation results. Desktop simulation system is the use of a personal computer to build a low-cost two-dimensional channel simulation system. It can be used for feasibility analysis of the preliminary design, and the design and evaluation of navigation aids. Part-mission driving simulator has three visual scenes and also has some general indicating instruments and operation handling with a good sense of on-site immersion. Typical full-mission ship driving simulator has more than 210 degrees 3-D projection screen. Real equipment is used for instruments, communication equipment and console, so the laboratory personnel have a very good sense of on-site immersion [10]. 


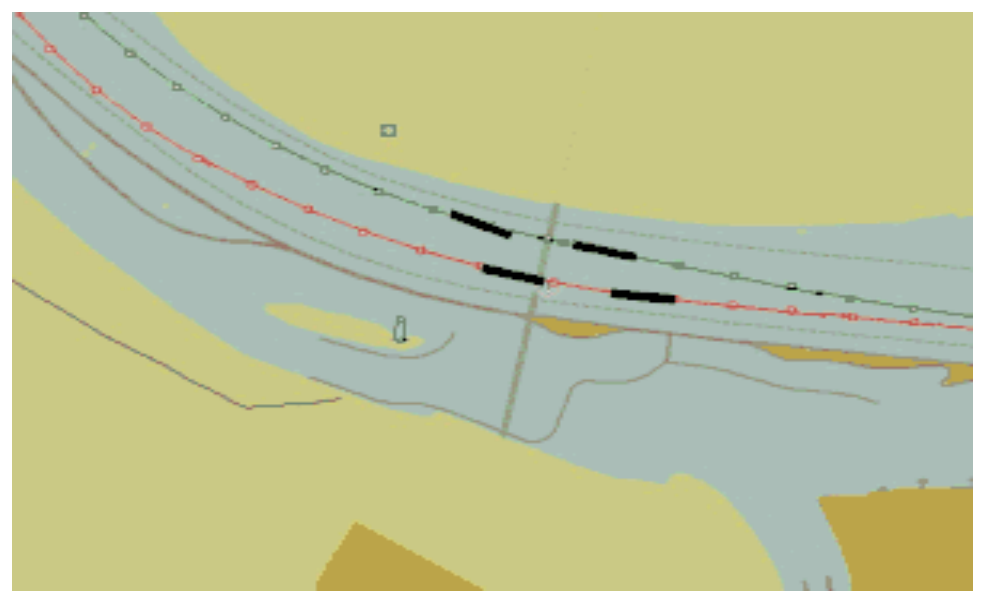

Fig. (3). Fairway vessel traffic flow simulation.

\section{B. Simulation of Vessel Traffic Flow}

Vessel traffic flow simulation refers to the microscopic motion simulation of the ship channel, and it does not require precise ship mechanical model to build scene models. The ship traffic flow simulation technology usually adopts intelligent technology (autonomous ship agents) in accordance with a defined route, the ship features and size of the vessel, vessel speed in the specified waterways obeying the traffic rules, regulations for preventing collisions and channel constraints for the automatic navigation, as shown in Fig. (2). The purpose is to identify vessel congestion, the risk of collision and grounding. Traffic flow simulation model can be used to simulate and analyze traffic incidents, but lacks a description of the physical characteristics of the ship. Use of vessel traffic flow simulation model which combines the ship's AIS data records can effectively evaluate the layout of navigational aids, and then put forward feasible modifications [11].

\section{KEY TECHNOLOGIES AND EVALUATION METHODS OF CHANNEL EMULATION}

In the simulation study of waterway engineering design, the ship motion model, ship traffic flow model and traffic scenes are the key technologies of event simulation environment. Simulation experiment combined with a variety of comprehensive evaluation of simulation technologies are the core methods of waterway design and simulation evaluation. Fairway vessel traffic flow simulation is shown in Fig. (3).

\section{A. Ship Motion Modeling}

In the simulation of the waterway, the ship motion's mathematical model determines the state of the ship movement, which directly affects the accuracy of ship maneuvering simulation fidelity. Accurate mathematical model for the ship's motion establishes one of the key technologies of waterway simulation evaluation. Forces on ship motion and affects by environment are well received by various operating personnel. Environmental effects can be produced by wind, current, quay effect, shallow water, the interactions of boats and waves. Manipulative force is received by rudder, trucks, tugs, thruster, ropes and anchors during operations. These forces lead ships to generate six degrees of freedom of motion: three horizontal movements (running, sliding and swing) and three vertical movements (heaving, rolling and pitching). Many ship driving simulator implements only three horizontal directions of motion, the mathematical model is:

$$
\begin{aligned}
& m\left(\dot{\mathrm{u}}-\mathrm{vr}-\mathrm{X}_{G} \mathrm{r}^{2}\right)=\mathrm{X} \\
& m\left(\dot{\mathrm{v}}+u \mathrm{r}+\mathrm{X}_{G} \mathrm{r}^{2}\right)=Y \\
& l_{Z} \dot{r}+m \mathrm{X}_{G}(\dot{\mathrm{v}}+u \mathrm{r})=N
\end{aligned}
$$

Wherein: $\mathrm{m}$ is the weight of ships; $\mathrm{I} Z \mathrm{Z}$ is turning inertia moment; $u$ is the speed of the front and rear direction; $v$ is the velocity of lateral offset; $r$ is the rate of rotation of the bow; $\mathrm{X}$ is the sum of the longitudinal force; $\mathrm{Y}$ is the sum of the lateral force; $\mathrm{N}$ is the sum of the vertical axes force moment; $X \_G$ is the centered position on the shaft. To calculate the power, a variety of factors must be determined. As it involves quite a lot of parameters, to determine the values of these parameters entails complex constraint model experiments and real boat testing and theoretical deduction. References can be seen in [12].

\section{B. Vessel Traffic Flow Modeling}

Vessel Traffic System is a complex system posed by the person, boat and the environment. It's difficult to describe the variation through determined analytical or empirical formulas. The application of simulation techniques for quantitative and qualitative research and analysis has become a costeffective tool which can demonstrate variation, optimize the system and provide a scientific basis. The waterway traffic flow modeling and simulation studies determine the fairway insecurity and assess the ability of movement through the waterway, thereby protecting the waterway and making it safe and efficient. A typical overall flow of vessel traffic simulation model is shown in Fig. (4). Vessel traffic flow 


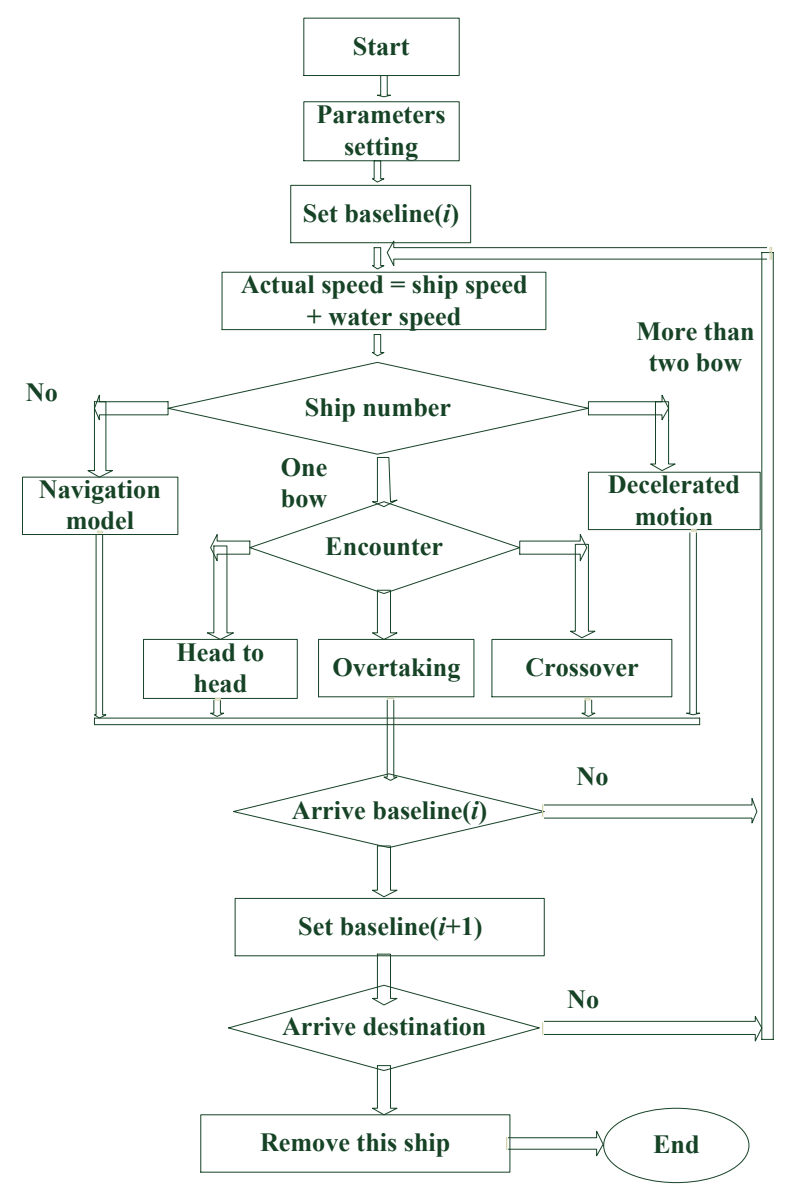

Fig. (4). Waterway vessel traffic flow simulation process.

simulation models are mainly involved in ship motion model, the deceleration model, encounter model, collision avoidance model, the cross encounter model [5], the calculation methods of the above models can be seen in the reference [5].

\section{Channel Simulation Scenario Modeling}

In the channel simulation system, the simulator scenarios include: buildings, ships, bow images, ports, waterways, etc., which can provide various visibilities in the daytime, evening and at night. As well as various other visual scenes and drawn realistic pictures of water, sky and land to simulate ship motion and tugs and other operations. Therefore, the ways to create 3D models for building waterway scene simulation system is very important. Currently, 3D computerized modeling scenarios are: gridded height field modeling, method of detail level modeling, voxel modeling method. Gridded height field terrain modeling approach is the traditional modeling methods. Suppose the terrain is a function of two variables, i.e. the point of each coordinates has a value to represent the height of the point. All considered, gridded height field distribution can be used to obtain 3D information. It is shown in the form of grid, with the height value of the each point coordinates fitted to grid, thus creating a height field. Sampling points in the form of a polygon mesh can be used to approximately describe the surface. In the pre-sampling, taking into account the difficulty of storage, specifically equilateral bi cubic patch and a square matrix can be adopted. Square matrix method can be more easily applied to the visual data generation of some ship handling simulator. LOD model can create multiple similar models, with different details describing the object for different models. The more accurate the description of the details, the more complicated the models are. LOD models are a new model of representation, changing the superficial idea of "the higher the quality, the better the image". The main direction of the line of sight, the residence time of the line of sight in the scene surface, the distance from the scene and the point of view, the size of the projection area of the scene on the screen and other factors determine the detail level of which the scenes could be selected to represent real-time display graphics. Furthermore, an analysis of the importance of each graphic object can ensure the most important objects gets higher quality graphics rendering, and a not so important graphic object gets lower quality rendering thus maximizing visual effects in real-time graphical display. On the automatically generated data model, the grid-based divided polygonal models are commonly used. Voxel model means "volume element" and has similar pixels with (pictorial element) and represents an object or collection of objects through the space occupied by pixel. The scanning device can provide us some of data and can be operated easily. This is the advantage. The modeling method can be obtained by two ways. One is to use a matrix, each unit simulating a small volume of space. Matrix entry has a value to represent some of the properties of area space, such as color or density, etc. to determine whether the volume of space has been occupied. When the cell is empty, it indicates that the corresponding space is not occupied. Another way is to use the Quad trees and Octal trees to realize the modeling method of allocating storage space to useful units [13].

\section{Methods of Simulation Experiment Assessment}

The simulation evaluation of the design of waterways and navigation aids is mainly for safety and the passing ability of waterway. The most common method of safety assessment is Formal Safety Assessment, FSA on the Safety Evaluation. The procedure for the establishment of fuzzy comprehensive evaluation model based on the general method of assessment model is: determining the evaluation system; ensuring each evaluation index weight; deciding the degree of membership of each evaluation index; modeling and its application. The evaluation sequence is shown in Fig. (5). Indicators involved in the safety assessment of waterways and navigation aids design are shown in Table 2.

The passing capacity of the waterway is usually indicated by the waterway traffic capacity. Waterway traffic capacity refers to the ability a waterway has to receive vessel traffic and is shown by the maximum number of vessels in per unit of time. Assuming, the performance and conditions of the ship are the same without prejudice to the traffic channel, the base waterway traffic capacity can be expressed as:

$$
C_{b}=W \cdot \rho_{\max } \cdot \mathrm{v}
$$




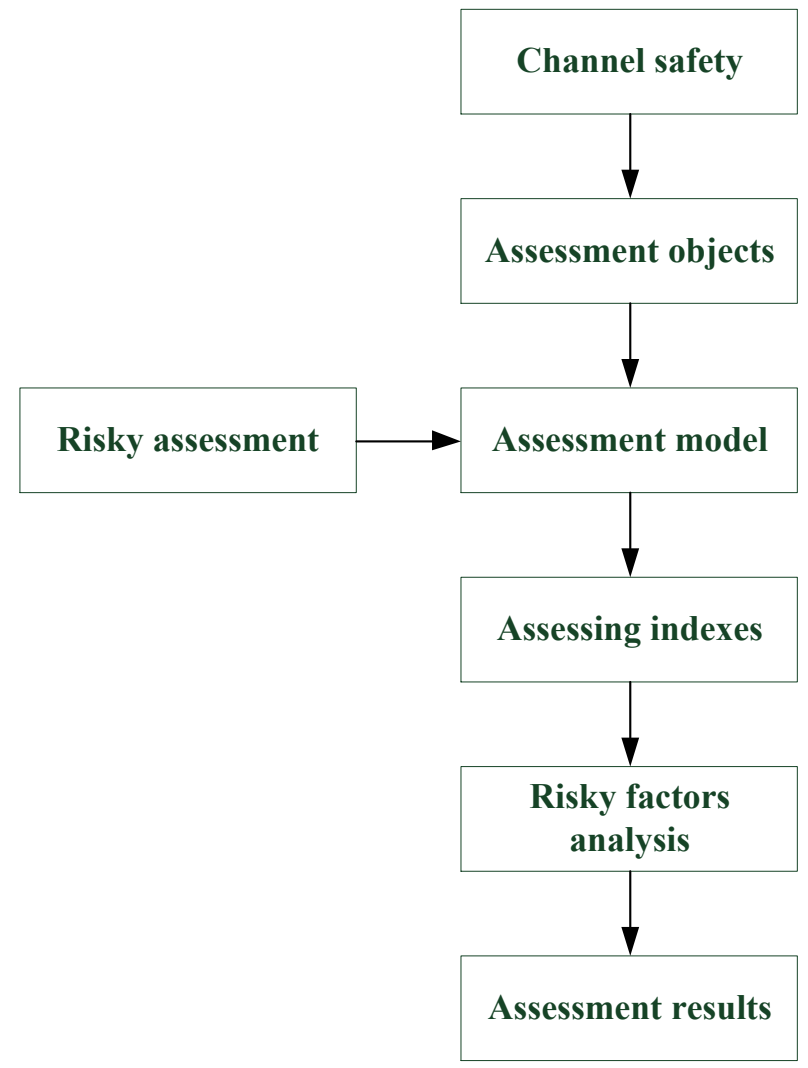

Fig. (5). Ship safety risk assessment model on the waterway.

Where: $C_{b}$ means the basic traffic capacity for the channel; $\mathrm{W}$ is the width of channel; $\rho_{\text {max }}$ the maximum density on a unit of channel width; $\mathrm{V}$ is the average speed of the ship. Through simulation experiments, the average speed of the ship and base traffic channel capacity can be calculated.

\section{CONCLUSION AND RESEARCH PROSPECTS}

As simulation technology can do qualitative and quantitative evaluation of the safety and efficiency of a complex system design and operation, it finds a wide application, in recent years, in waterway engineering feasibility analysis, preliminary design and design effects evaluation. This article entails the implementation processes of the simulation de- sign and evaluation in the waterways and navigation aids, and the analysis of advantages and disadvantages of several simulation system commonly used and the application scope. Moreover, it analyzes the key technologies adopted in the fairways and navigation aids design and simulation to provide some technical guidance for conducting studies in this field.

With national attention on inland waterways, waterway construction is in a major period of great development. The trend of shipping prosperity and large ships lays high standards on inland waterways system safety and smooth flow, so simulation will be needed in the inland waterway system design. Despite simulation's mature application in the port channel and navigation aids design and evaluation, simulation application in inland waterways system design and evaluation still faces technical and methodological problems, which are mainly reflected in:

1) Ship motion modeling: There are many shallow waterways, restricted waters, waters with a quay effect in the inland waterways, and in those complex waterways, it is important to build accurate model of ship motion and do real-time computing for establishing simulation system for inland waterway vessels.

2) Vessel traffic flow modeling: In recent years, inland waterway route conditions have been improved, the implementation of river designed routing makes waterway transport and road traffic have some similarities. Many scholars have therefore adopted the theory of traffic flow method to carry out inland waterway traffic flow model study. However, inland waterways with uncertainty of water velocity, flow, depth and distribution, the interaction between ships, heavy regional traffic and other factors, needs further study to build an ideal inland waterway traffic flow model.

3) Construction of low-cost generic simulation system of inland waterways: Full -mission waterways simulation systems are expensive, limiting its application areas and scope. Inland navigation system has more users, and the size of companies and research units are far less than shipping system unit, so it is of practical significance to build low-cost inland waterways simulation system. Currently, combined with the latest virtual reality and computerized 3D visualization technology, to develop inland waterways simulation system is already technically feasible.

Table 2. safety assessment indicators of waterways and navigation aids.

\begin{tabular}{|c|c|c|c|c|c|}
\hline Vessel Conditions & Traffic Conditions & $\begin{array}{c}\text { Navigable } \\
\text { Conditions }\end{array}$ & $\begin{array}{c}\text { Waterway } \\
\text { Conditions }\end{array}$ & Indirect Consequence \\
Consequence
\end{tabular}


4) Accurate waterway scene modeling techniques: Inland waterway scene has complicated content, especially when water level, flow velocity, flow pattern in hydrological environment have temporal uncertainties. Therefore, it is hard to accurately model and show it in the fairway scene. And it is one of the key technologies in building inland waterway simulation system.

5) Lock simulation technology: Lock is a special waterway facility, it is necessary to solve the problems of the ship approach rules when the ship is sailing against the current or with it supports behavior analysis when the ship is in the lock.

6) Evaluation techniques with human factors: Inland waterway transport system is a complex system of humans Boats - Fairway. People in the simulation system loop help improve the accuracy of the simulation results. While the people in the loop simulation experimental design, experimental data collection, data analysis techniques, the methods, and standards shall be analyzed deeply.

7) Visual aids design evaluation techniques. Visual navigation marks are important waterway navigation aids which play an important role in the protection of inland waterway safety and smooth flow. Visual effects space model of visual navigation marks and the attenuation model in different weather conditions is the basis for visual simulation design and evaluation constructed based on simulation inland waterway. Meanwhile, the human simulation evaluation criteria and methods should also be discussed deeply in the visual navigation marks experiment.

8) Radio navigation aids effectiveness evaluation techniques: In recent years, AIS, VTS, radar transponders, electronic path maps and some other radio navigation aids are gradually promoted in inland navigation system and the effectiveness evaluation is also an important direction of inland waterway simulation system which will address issues like radio navigation aids modeling and scenes display, HCI ergonomics evaluation and so on.

In summary, the inland waterway engineering simulation evaluation techniques still has many problems to be solved, and it is of great significance to carry out research in this field for the promotion of inland waterway engineering science development.

\section{CONFLICT OF INTEREST}

The author confirms that this article content has no conflict of interest.

\section{ACKNOWLEDGEMENTS}

The writers would like to acknowledge the support from the Education Scientific Research Project of Young Teachers in Fujian Province Grant No. JA13251 and Fuzhou Planning Project of Science and Technology Grant No. 2013-S-115 and Minjiang University recruiting talents research projects.

\section{REFERENCES}

[1] W.L. Delft Hydraulics \& MARIN. SHIPMA 6.1 - "A fast-time simulation program for ship maneuvering” (user manual). MARIN, Wageningen, The Netherlands.

[2] M. H. A. Kaarsemaker, O. M. Weiler, G. Kantand, and H. J. Verheij, "Evaluation of Flow Fields for their Impact on Manoeuvring”, PIANC MMX Congress Liverpool: UK, 2010.

[3] Shallow-Water Navigation Simulator. http://www.dst-org.de/projekte/projekte/simulator/Flyer\%20Englisch.pdf

[4] H. Watanabe, K. Hasegawa, and P. Rigo, "Inland Waterway Traffic Simulator", http://orbi.ulg.ac.be /bitstream/2268/36403/1/COMPIT08_Inland.pdf

[5] S. Y. Chen, and Z. P. Shao, "Harbor waterway traffic flow simulation model", Dalian Maritime University, vol. 1, pp. 34-38, 2001.

[6] H. Z. Qian, "Incoming ship handling simulator in applied research on the design argument", Chinese Sailing, vol. 1, pp. 41-45, 2003.

[7] X. W. Kong, J. H. Li, and X. X. Feng, "Ship simulator works in Ji Han River and the Yangtze River confluence navigable layout application", Waterway and Harbor, vol. 4, pp. 7-11, 2010.

[8] The Use of Simulation as a Tool for Waterway Design and AtoN Planning. http://www.iala-aism.org/iala/publications /.../doc_302 _eng.pdf

[9] F. Bronaugh, 'Human-in-the-loop' simulation: The right tool for port design, www.portechnology.org

[10] X. L. Bian, "Ship handling simulation design application in the fairway", China Water Transport, vol. 3, pp. 48-50, 2006.

[11] J. Shi, J. B. Chen, and Q. Y. HU. Ship handling simulator development and application of global collaboration. China: Shanghai Maritime University, vol. 3, pp. 1-6, 2007.

[12] The Specialist Committee on Esso Osaka, Final Report and Recommendations to the $23^{\text {rd }}$ ITYC, Proceedings of $23^{\text {rd }}$ International Towing Tank Conference, pp. 581-617, 2002.

[13] X. H. Ma, "LOD Study of Models at multiple level detail in Virtual Reality", $\mathrm{PhD}$ thesis of Zhejiang University, 1997.

Received: September 22, 2014

Revised: November 03, 2014

Accepted: November 06, 2014

(C) He et al.; Licensee Bentham Open.

This is an open access article licensed under the terms of the Creative Commons Attribution Non-Commercial License (http://creativecommons.org/licenses/by-nc/3.0/) which permits unrestricted, non-commercial use, distribution and reproduction in any medium, provided the work is properly cited. 